\title{
Clinical pharmacist assessment of drug-related problems among intensive care unit patients in a Turkish university hospital
}

\author{
Aslınur Albayrak*, Bilgen Başgut ${ }^{2}$, Gülbin Aygencel Bıkmaz ${ }^{3}$ and Bensu Karahalil ${ }^{4}$
}

\begin{abstract}
Background: Critically ill patients treated in the intensive care units (ICUs) often suffer from side effects and drugrelated problems (DRPs) that can be life-threatening. A way to prevent DRPs and improve drug safety and efficacy is to include clinical pharmacists in the clinical team. This study aims to evaluate the classification of drug-related problems and the implementation of clinical pharmacy services by a clinical pharmacist in the ICU of a university hospital in Turkey.

Methods: This study was carried out prospectively between December 2020 and July 2021 in Gazi University Medical Faculty Hospital Internal Diseases ICU. All patients hospitalized in the intensive care unit for more than $24 \mathrm{~h}$ were included in the study. During the study, the clinical pharmacist's interventions and other clinical services for patients were recorded. DRPs were classed according to the Pharmaceutical Care Network Europe V.8.02.
\end{abstract}

Results: A total of 151 patients were included during the study period corresponding to 2264 patient-days. Patients with DRPs had a longer hospital stay and a higher mortality rate $(p<0.05) .108$ patients had at least one DRP and the total number of DRPs was 206. There was an average of 1.36 DRPs per patient, $71.5 \%$ of patients experienced DRP and 89.22 DRPs per 1000 patient-days. A total of 35 ADEs were observed in 32 patients. ADE incidence was per 1000 patient-days 15.45. ADEs were caused by nephrotoxicity (48.57\%), electrolyte disorders (17.14\%), drug-induced thrombocytopenia (17.14\%), liver enzyme increase (8.57\%) and other causes (8.57\%). Drug selection (40.29\%) and dose selection (54.36\%) constituted most of the causes of DRPs. Dose change was the highest percentage of planned interventions with a rate of $56.79 \%$. Intervention was accepted at a rate of $90.8 \%$ and it was fully implemented.

Conclusion: In this study, the importance of the clinical pharmacist in the determination and analysis of DRPs was emphasized. Clinical pharmacy services like the one described should be implemented widely to increase patient safety.

Keywords: Clinical pharmacist, Drug-related problem, Intensive care unit, PCNE, Adverse drug events,

Pharmaceutical care

*Correspondence: a.albayrak007@gmail.com; aslinuralbayrak@gazi.edu.tr 1 Department of Clinical Pharmacy, FacultyofPharmacy, Gazi University, Ankara, Turkey

Full list of author information is available at the end of the article

\begin{abstract}
Background
Critically ill patients in the intensive care units (ICUs) often suffer from some side effects and drug related problems (DRPs) that can be life-threatening [1]. Multiple organ failure and polypharmacy increase the risk of DRPs. DRP can be described as an incident or condition comprising drug treatment that actually or potentially
\end{abstract}


intervenes the wished health outcomes. Most DRPs are presumable and potentially avoidable, and their frequency can be diminished with rational drug use $[2,3]$.

A way to prevent DRPs and improve drug safety and efficacy is to include clinical pharmacists in the clinical team. By identifying and resolving DRPs, clinical pharmacists can prevent adverse drug events from occurring [4-6]. Studies have shown that clinical pharmacists' participation in multidisciplinary teams reduces the length of stay in the ICU and mortality [7, 8]. Additionally, economic evaluations of clinical pharmacy services in the ICU consistently demonstrate the potential for significant cost savings and reduce the workload of ICU staff $[5,9]$.

The concept of clinical pharmacy, which was first advocated in the United States in the 1950s, was not introduced to Turkey until the 1990s [10]. Currently, there are masters, doctorate and specialization programs in Turkey. There is still insufficient number of academic staff and few clinical pharmacists routinely work in hospitals. Although there are many studies evaluating the impact of the clinical pharmacist in intensive care units $[7,11$, 12], there are many differences between international health systems such as health management, local population numbers and pharmacist education. Studies related to the implementation of clinical pharmacy services, such as identifying drug-related problems, are critical for developing countries where clinical pharmacy services are emerging. This is the first comprehensive study evaluating clinical pharmacist practices in intensive care in Turkey.

This study aims to evaluate the classification of drugrelated problems and the implementation of clinical pharmacy services by a clinical pharmacist in the intensive care unit of a university hospital in Turkey.

\section{Methods}

\section{Study design and participants}

This study was conducted prospectively between December 2020 and July 2021 in Gazi University Medical Faculty Hospital ICU of Internal Diseases Ward. There are 9 beds in the ICU of Internal Diseases Ward in the hospital.

The sample size (n) was estimated using the single population proportion formula for the finite population [13, 14]. $n=\mathrm{N}^{*} \mathrm{X} /(\mathrm{X}+\mathrm{N}-1)=200 * 384.16 /(384.16+200-$ $1)=132$, where $X=Z^{2} * p^{*}(1-p) / E^{2}$, and $Z=1.96$ at $95 \%$ confidence level, $\mathrm{E}$ is the margin of error $(0.05), \mathrm{p}$ is the sample proportion (assigned $50 \%$ as the most conservative assumption), and $\mathrm{N}$ is the average population size.

All patients hospitalized in the ICU for more than $24 \mathrm{~h}$ were included in the study. Three doctors, one professor, one associate professor, and one assistant professor, work in the ICU. Specialist and resident physicians also work alternately. Only one clinical pharmacist worked in the study. There was no clinical pharmacist working in these clinics before the study. This study was confirmed by Gazi University Faculty of Medicine Clinical Research Ethics Committee, Ankara/Turkey and was conducted according to the Declaration of Helsinki and Good Clinical Practice (GCP). (No:700/02.11.2020).

\section{Data collection}

During the study, the clinical pharmacist's interventions and other clinical services for patients were recorded. The data collection form was filled within $48 \mathrm{~h}$ of the patient's admission to the hospital. The form comprised demographics, patient history, patient diagnosis, chief complaint, history of active illness, comorbidities, family history, laboratory parameters, past medication history and daily medication list. Clinical pharmacist obtained data from electronic medical records, direct observation and visits. Additionally, clinical decision-making tools such as UpToDate ${ }^{\circledR}$, Medscape ${ }^{\circledR}$, Lexicomp Online ${ }^{\circledR}$, Sanford Guide to Antimicrobial Therapy Mobile and National Kidney Foundation mobile application were used. After the suspicious DRPs were determined by the clinical pharmacist, a decision was made by discussing with the physician and nurse. PCNE Classification v.8.02 for was used to categorise DRPs by problem type, cause, planned intervention, proposed intervention, and outcome [15]. DRPs per patient were used to assess the incidence of DRP.

\section{Data analysis}

The following variables defined the sample: age, sex, length of stay, reason for admission to the intensive care unit, mortality, and prognostic scores. Acute Physiology and Chronic Health Assessment II (APACHE II) and Sequential Organ Failure Assessment (SOFA) were obtained. Considering the parameters of admission to the intensive care unit. SPSS Software for Windows, version 20.0 (IBM, Armonk, NY) was used for the data analysis. Descriptive statistics were expressed as frequency and percentage, and the non-descriptive data were expressed as median. $\chi^{2}$ test and Mann-Whitney $U$ test were used to compare categorical and continuous variables, respectively. $P$-value of $<0.05$ was considered statistically significant.

\section{Results}

During the study period, which corresponds to 2264 patient days, 151 patients were involved in our study. The causes for admission to the ICU are mainly respiratory system problems (60.9\%) and sepsis (72.2\%). Patients with DRPs had longer hospital stays and higher mortality rates than patients without DRPs $(p<0.05)$. 
APACHE II and SOFA scores did not change by DRP status $(p>0.05)$. Patient characteristics are shown in Table 1.

Table 2 presents the DRP classification. Clinical pharmacists evaluated all the patients, and 108 patients (71.5\%) had at least one DRP and the total number of DRPs was 206. There was a mean of 1.36 DRPs per patient, with $71.5 \%$ of patients experienced DRP and 89.22 DRPs per 1000 patient-days. The most potential or observed problems were adverse drug events (ADEs) (77.18\%). Most of the causes of DRPs are drug selection (40.29\%) and dose selection (54.36\%). Inappropriate drug or drug combination and herbal medicine (35.43\%) had the highest percentage of drug selection. The highest percentage of planned interventions was dose changes with $56.79 \%$. Intervention was accepted at a rate of $90.8 \%$ and it was fully implemented. Table 3 contains some examples of clinical pharmacist recommendations. As can be seen in Table 3, drug renal dose adjustment recommendations are quite high.

A total of 35 ADEs were observed in 32 patients. ADE incidence was per 1000 patient-days 15.45. ADEs were caused by nephrotoxicity (48.57\%), electrolyte disorders (17.14\%), drug-induced thrombocytopenia (17.14\%), liver enzyme increase (8.57\%) and other causes (8.57\%). Piperacillin-tazobactam, linezolid, and heparin are examples of drug-induced thrombocytopenia. Colistin is the major drug responsible for nephrotoxicity. Trimethoprim-sulfamethoxazole-induced hyperkalemia is an example of electrolyte disturbances (Table 4).

\section{Discussion}

The study showed the significance of the clinical pharmacist's participation in the intensive care team. Most recommendations $(90.8 \%)$ made by the clinical pharmacist were accepted and fully implemented by the physician.

In the study by Jiang et al. [16] the incidence of DRP per 1000 patient-days was $124.7,112.94$ in the study by Martin et al. [17] 65.1 in the study by Sakuma et al. [18]. In our study, this ratio was 89.22 . These different results can be arised from various factors such as technological resources, ICU environment-specific characteristics, the method used for DRP detection, and the accepted description of DRP. Low frequencies are often seen in hospitals where a clinical pharmacist is integrated into the intensive care team [19-21].

Patients hospitalized in the ICU are exposed to polypharmacy due to their multiple comorbidities, organ dysfunction and are more prone to drug-drug interactions [5]. Most of these drugs are antimicrobials. Particularly, most of the patients hospitalized in ICUs had renal dysfunction. It is important to monitor the daily renal dose in these patients and to make dose adjustments when receiving renal replacement therapy [22, 23]. In this study, most of the DRPs were caused by inappropriate drug combinations (35.43\%), overdose (24.27\%) and low-dose (14.56\%). In addition, dose changes (56.79\%) were made in most of the interventions. Considering the other studies, drug discontinuation $(23.6 \%)$ and inappropriate dose frequency (22.2\%) [24], drug change (22.8\%) and dose change (7.3\%) [25], inappropriate drug

Table 1 Patient characteristics during the observation period in the intensive care unit $(n=151)$

\begin{tabular}{|c|c|c|c|c|}
\hline & Total (\%) & No DRP (\%) & Experienced DRP (\%) & $p$ \\
\hline Number of patients & 151 & $43(28.5)$ & $108(71.5)$ & \\
\hline Male & $95(62.9)$ & $27(62.8)$ & $68(68)$ & $0.984^{b}$ \\
\hline Female & $56(37.1)$ & $16(37.2)$ & $40(37)$ & \\
\hline Age median & $69(25-93)$ & $68(31-86)$ & $69(30-93)$ & $0.345^{\mathrm{a}}$ \\
\hline Length of stay, days & $10(1-97)$ & $7(1-40)$ & $11(1-97)$ & $0.001^{a}$ \\
\hline SOFA at admission & $7(0-22)$ & $7(0-14)$ & $7(1-22)$ & $0.715^{\mathrm{a}}$ \\
\hline APACHE ॥ & $21(5-40)$ & $21(6-33)$ & $21(5-40)$ & $0.852^{\mathrm{a}}$ \\
\hline ICU mortality & $117(77,5)$ & $28(65.1)$ & $89(82.4)$ & $0.022^{b}$ \\
\hline \multicolumn{5}{|l|}{ Admission diagnosis - ICD 10} \\
\hline J00-J99 Diseases of the respiratory system & $92(60.9)$ & $28(65.1)$ & $64(59.2)$ & $0.581^{b}$ \\
\hline N00-N99 Diseases of the genitourinary system & $11(7.3)$ & $2(4.7)$ & $9(8.3)$ & $0.729^{d}$ \\
\hline K00-K93 Diseases of the digestive system & $12(7.9)$ & $1(2.3)$ & $11(10.2)$ & $0.180^{d}$ \\
\hline 100-199 Diseases of the circulatory system & $16(10.6)$ & $3(7)$ & $13(12)$ & $0.559^{d}$ \\
\hline A41.9 Sepsis & $109(72.2)$ & $29(67.4)$ & $80(74.1)$ & $0.412^{b}$ \\
\hline R65.21 Septic Shock & $33(21.9)$ & $11(25.6)$ & $22(20.4)$ & $0.484^{c}$ \\
\hline N17.9 Acute Renal Failure & $46(30.5)$ & $11(25.6)$ & $35(32.4)$ & $0.411^{b}$ \\
\hline
\end{tabular}

SOFA Sequential Organ Failure Assessment, APACHE Acute Physiology and Chronic Health Evaluation II, ICU Intensive Care Unit, ICD10 International Statistical Classification of Diseases and Related Health Problems, 10 th Revision, ${ }^{a}$ Mann Whitney $U$ test, ${ }^{b}$ Pearson's $X 2$ test, ${ }^{c}$ Continuity corrected $X 2$ test, ${ }^{d}$ Fisher's exact test 
Table 2 Classification of identified drug-related problems according to the Pharmaceutical Care Network Europe Foundation

Drug-related problems (DRPs) detected

Patients experiencing DRP (\%)

Cumulative incidence (DRP/patient)

Incidence density rate (DRP/1000 patient-days)

Potential or manifest problems

P1.2 Effect of drug treatment not optimal

P2.1 Adverse drug event occurring

P3.1 Problem with cost-effectiveness of the treatment

P3.2 Unnecessary drug-treatment

$4(1.94 \%)$

DRP causes

Drug Selection

C1.2 Inappropriate drug (within guidelines but otherwise contra-indicated)

$9(4.36 \%)$

C1.4 Inappropriate combination of drugs or drugs and herbal medication

$73(35.43 \%)$

C1.5 Inappropriate duplication of therapeutic group or active ingredient

$1(0.48 \%)$

Dose Selection

C3.1 Drug dose too low

C3.2 Drug dose too high

C3.3 Dosage regimen not frequent enough

C3.4 Dosage regimen too frequent

C3.5 Dose timing instructions wrong, unclear or missing

Drug use process

C6.1 Inappropriate timing of administration and/or dosing intervals

Other

The planned interventions at prescriber level

11.1 Prescriber informed only

11.3 Intervention proposed to prescriber

The planned interventions at drug level

13.1 Drug changed

13.2 Dosage changed

13.4 Instructions for use changed

13.5 Drug stopped

13.6 New drug started

Acceptance of the intervention proposals

A1.1 Intervention accepted and fully implemented

A1.3 Intervention accepted but not implemented

A2.1 Intervention not accepted: not feasible

A2.2 Intervention not accepted: no agreement

A3.1 Intervention proposed, acceptance unknown

Outcome of intervention

O1.1 Problem totally solved

$165(80.09 \%)$

O2.1 Problem partially solved

combinations, inappropriate dose intervals (40.45\%), dose change (24.09\%) [17] [8] inappropriate dosing (37.3\%) and drug omission (20.4\%) [16] constituted most DRPs. Differences between these studies can be justified by different populations, countries and the competence of healthcare providers. In the hospital where this study was conducted, it was in close cooperation with the ICU infection team. Therefore, the duration of treatment of antimicrobials was appropriate and drug omission had not been encountered. 
Table 3 Examples of clinical pharmacist recommendations*

\begin{tabular}{|c|c|}
\hline Recommendation category & Sample pharmacist recommendation \\
\hline \multicolumn{2}{|l|}{ DRP causes } \\
\hline \multicolumn{2}{|l|}{ C1.2 Inappropriate drug (within guidelines but otherwise contra-indicated) } \\
\hline Use of metoclopramide in patients over 65 years of age & Medication change was recommended \\
\hline \multicolumn{2}{|l|}{ C1.4 Inappropriate combination of drugs or drugs and herbal medication } \\
\hline Meropenem-Valproic acid & It was recommended to stop the use of meropenem \\
\hline Ciprofloxacin-Enteral nutrition & $\begin{array}{l}\text { It was recommended to take a 1-h break from feeding before and after } \\
\text { ciprofloxacin administration }\end{array}$ \\
\hline Phenytoin-Enteral nutrition & $\begin{array}{l}\text { It was recommended to take a 1-h break from feeding before and after } \\
\text { phenytoin administration }\end{array}$ \\
\hline Clarithromycin-Midazolam & A reduction in midazolam dose was recommended \\
\hline \multicolumn{2}{|l|}{ C1.5 Inappropriate duplication of therapeutic group or active ingredient } \\
\hline Tiotropium bromid- ipratropium bromide & It was recommended to stop ipratropium bromide \\
\hline \multicolumn{2}{|l|}{ C3.1 Drug dose too low } \\
\hline Use of meropenem IV $0.5 \mathrm{~g}$ twice a day in a patient receiving CRRT & $\begin{array}{l}\text { It was recommended to increase the dose of meropenem to } 1 \mathrm{~g} \text { twice a } \\
\text { day }\end{array}$ \\
\hline Use of Ampicillin sulbactam IV $2 \mathrm{~g}$ twice a day & It was recommended to increase the dose to $3 \mathrm{~g} 3$ times a day \\
\hline \multicolumn{2}{|l|}{ C3.2 Drug dose too high } \\
\hline Use of Colistin IV 150 mg twice a day & $\begin{array}{l}\text { It was recommended to reduce the dose to } 110 \mathrm{mg} \text { twice a day in the } \\
\text { patient with a } \mathrm{CrCl} \text { of } 50\end{array}$ \\
\hline Use of Fluconazole IV 400 mg & $\begin{array}{l}\text { It was recommended to reduce the dose to } 200 \mathrm{mg} \text { in patients with a } \mathrm{CrCl} \\
\text { below } 50\end{array}$ \\
\hline \multicolumn{2}{|l|}{ C3.3 Dosage regimen not frequent enough } \\
\hline Use of Teicoplanin every $72 \mathrm{~h}$ & It was recommended to be every $48 \mathrm{~h}$ in patients receiving CRRT \\
\hline \multicolumn{2}{|l|}{ C3.4 Dosage regimen too frequent } \\
\hline Teicoplanin every $48 \mathrm{~h}$ & It was recommended to be every $72 \mathrm{~h}$ in patients receiving hemodialysis \\
\hline Ranitidine IV 50 mg 3 times per day & $\begin{array}{l}\text { It was recommended to reduce the dose to } 50 \mathrm{mg} \text { once a day in patients } \\
\text { with a } \mathrm{CrCl} \text { below } 50\end{array}$ \\
\hline \multicolumn{2}{|l|}{ C3.5 Dose timing instructions wrong, unclear or missing } \\
\hline Not taking additional doses after dialysis in the treatment of colistin & An additional 50 mg dose was recommended after hemodialysis \\
\hline No or missing colistin loading dose & 300 mg colistin loading dose was recommended \\
\hline \multicolumn{2}{|l|}{ C6.1 Inappropriate timing of administration and/or dosing intervals } \\
\hline Clarithromycin IV 500 mg 2 times a day & $\begin{array}{l}\text { In patients receiving hemodialysis or with a } \mathrm{CrCl} \text { less than } 10,500 \mathrm{mg} \text { once } \\
\text { daily was recommended }\end{array}$ \\
\hline Use of teicoplanin in patients receiving plasmapheresis & $\begin{array}{l}\text { Since teicoplanin is a highly protein-bound drug, it was recommended to } \\
\text { be given at least } 4 \mathrm{~h} \text { after plasmapheresis }\end{array}$ \\
\hline
\end{tabular}

IV Intravenous, $\mathrm{CrCl}$ Creatinine Clearance, CRRT Continuous Renal Replacement Therapy, mg milligram, $g$ gram

* These examples were selected as important by the authors after reviewing the records of the recommendations

The incidence of ADR was 15.45 per 1000 patient-days, which is low compared to other studies; for example, Rothschild [1] detected 80 events per 1000 patient-days, Sakuma et al. [18] 37.8 events, Smithburger et al. [26] 76.2 events. Most of the adverse effects observed in our study are colistin-induced nephrotoxicity. Colistin is frequently used in ICUs for treating of multidrug-resistant (MDR) infections and as a salvage therapy [27]. For this reason, it is important to adjust the daily renal dose and pay attention to the drugs used simultaneously. Additionally, druginduced thrombocytopenia and electrolyte disturbances were common adverse events in our study. As with other studies, most ADEs were due to antimicrobials [17, 28].
Abunahlah et al. [29] and Ertuna et al. [30] are examples of studies evaluating clinical pharmacy services in Turkey in internal medicine and geriatric services, respectively. According to studies, DRPs per patient is $1.63 \pm 1.21$ and $1.66 \pm 0.11$, which is slightly higher than our study. Similar to our study, drug selection (especially drug-drug interaction) and dose selection were the most important reasons of drug-related problems in both studies. In the study of Ertuna et al.[30], clinical pharmacy interventions were accepted at a rate of $85 \%$, which is slightly lower than in our study.

Drug-drug interactions have a significant percentage (\%35.43) in the interventions proposed in our study. 
Table 4 Drugs that cause observed adverse drug events

\begin{tabular}{ll}
\hline Patients experiencing adverse drug reactions (\%) & $32(21.19)$ \\
Cumulative incidence (ADE/patient) & 0.23 \\
Incidence density rate (ADE/1000 patient-days) & 15.45 \\
Adverse drug events detected & 35 \\
Drug-induced thrombocytopenia & $6(17.14 \%)$ \\
Piperacillin tazobactam & $3(8.57 \%)$ \\
Linezolid & $2(5.71 \%)$ \\
Heparin & $1(2.85 \%)$ \\
Nefrotoxicity & $17(48.57 \%)$ \\
Colistin & $16(45.71)$ \\
Apixaban & $1(2.85 \%)$ \\
Increase in liver enzymes & $3(8.57 \%)$ \\
Tigecycline & $2(5.71 \%)$ \\
Meropenem & $1(2.85 \%)$ \\
Electrolyte disorder (K+, Na+) & $6(17.14 \%)$ \\
Trimethoprim-sulfamethoxazole induced hyperkalemia & $3(8.57 \%)$ \\
Heparin induced hyponatremia & $1(2.85 \%)$ \\
Carbamazepine induced hyponatremia & $1(2.85 \%)$ \\
Escitalopram-induced hyponatremia & $1(2.85 \%)$ \\
Other & $3(8.57 \%)$ \\
Ciprofloxacin-associated seizures & $1(2.85 \%)$ \\
Midazolam over-sedation & $1(2.85 \%)$ \\
Metformin induced lactic acidosis & $1(2.85 \%)$ \\
\hline
\end{tabular}

Critically ill patients are more sensitive to the occurrence of drug interactions as they involve various organ failure and necessitate treatment with multiple drug combinations. Drug interactions are mainly due to administration of drugs that alter cytochrome P450 activity. [31]. The interaction of drugs that prolong the QT interval was among our interventions due to the risk of cardiotoxicity, arrhythmias and cardiac arrest.

The bioavailability of ciprofloxacin, phenytoin in the enteral feeding tube decreases by $27 \%-67 \%$. The American Parenteral and Enteral Nutrition Association (ASPEN) recommend discontinuing enteral feeding 30 min before and 30 min after administration of drugs, such as ciprofloxacin whose absorption properties are affected by enteral nutrition [32]. However, many studies suggest taking a break $1-2 \mathrm{~h}$ before and $1-2 \mathrm{~h}$ after drug administration, as in our study [33].

During plasmapheresis, highly protein-bound drugs such as ceftriaxone and teicoplanin can be removed [34, 35]. In this context, the time of administration of these drugs is important. In our study, we made our recommendations on this subject according to the literature data. For example, we recommended that teicoplanin should be given at least $4 \mathrm{~h}$ after plasmapheresis.

Our recommendation acceptance rate (90.8\%) was high considering that clinical pharmacy services are newly developing in Turkey and are comparable to the acceptance rates in other studies (61.8\%-99.2\%) [16, 17, 24, 36].

There are some limitations of our study. These are working in a single center, in a single intensive care unit and with a limited number of patients. Future studies should be conducted with a larger patient population with more than one clinical pharmacist evaluating the effect of the clinical pharmacist in more than one intensive care unit.

Currently, clinical pharmacy is a new field in Turkey. Our study has determined drug-related problems and shows that clinical pharmacy services should be implemented and expanded in Turkey. Additionally, our recommendations were highly accepted in our study. This is a great opportunity to show that physicians in Turkey are willing to work with clinical pharmacists.

\section{Conclusions}

In this study, the importance of the clinical pharmacist in the determination and analysis of DRPs was emphasized. In our study, most DRPs were caused by inappropriate drug combinations and high doses. Our study showed that clinical pharmacy services are necessary and should be implemented in ICUs in Turkey. Further studies are required to show the effect of clinical pharmacist activities in ICUs.

\section{Abbreviations \\ ICUs: Intensive care units; DRP: Drug related problem; APACHE II: Acute Physiology and Chronic Health Evaluation II; SOFA: Sequential Organ Failure Assessment.}

\section{Acknowledgements}

We would like to thank both reviewers of this article for their valuable suggestions.

\section{Authors' contributions}

$A A$ and $B B$ designed the study; BB, AA, GAB collected datas; $A A, B K, B B, G A B$ interpreted the results, and wrote the manuscript. All authors read and approved the final manuscript.

\section{Funding}

The authors received no specific funding for this work.

\section{Availability of data and materials}

All data generated or analyzed during this study are included in this published article.

\section{Declarations}

Ethics approval and consent to participate

This study was approved by the Institutional Review Board of Gazi University Faculty of Medicine, Ankara/Turkey and was conducted according to the Declaration of Helsinki and Good Clinical Practice (GCP). (No:700/02.11.2020). Written informed consent was obtained from the adult ( $>18$ years old) patients who participated in this study.

\section{Consent for publication}

Not applicable 


\section{Competing interests}

The authors declare that they have no competing interests.

\section{Author details}

${ }^{1}$ Department of Clinical Pharmacy, FacultyofPharmacy, Gazi University, Ankara, Turkey. ${ }^{2}$ Department of Pharmacology, Faculty of Pharmacy, Baskent University, Ankara, Turkey. ${ }^{3}$ Department of Intensive Care, Faculty of Medicine, Gazi University, Ankara, Turkey. ${ }^{4}$ Department of Pharmaceutical Toxicology, Faculty of Pharmacy, Gazi University, Ankara, Turkey.

Received: 4 October 2021 Accepted: 12 January 2022

Published online: 15 January 2022

\section{References}

1. Rothschild JM, Landrigan CP, Cronin JW, Kaushal R, Lockley SW, Burdick E, et al. The Critical Care Safety Study: The incidence and nature of adverse events and serious medical errors in intensive care. Read Online: Crit Care Med. 2005:33(8):1694-700.

2. Ridley S, Booth S, Thompson C, Incidents ICSSWGoA. Prescription errors in UK critical care units. Anaesthesia. 2004;59(12):1193-200.

3. Cullen DJ, Sweitzer BJ, Bates DW, Burdick E, Edmondson A, Leape LL. Preventable adverse drug events in hospitalized patients: a comparative study of intensive care and general care units. Crit Care Med. 1997;25(8):1289-97.

4. Abdelaziz K, Abdelrahim ME. Identification and categorisation of drugrelated problems on admission to an adult intensive care unit. Eur J Hosp Pharm. 2015:22(3):138-41.

5. Kane SL, Weber RJ, Dasta JF. The impact of critical care pharmacists on enhancing patient outcomes. Intensive Care Med. 2003;29(5):691-8.

6. Calabrese AD, Erstad BL, Brandl K, Barletta JF, Kane SL, Sherman DS. Medication administration errors in adult patients in the ICU. Intensive Care Med. 2001;27(10):1592-8.

7. Lee H, Ryu K, Sohn Y, Kim J, Suh GY, Kim E. Impact on patient outcomes of pharmacist participation in multidisciplinary critical care teams: a systematic review and meta-analysis. Read Online: Crit Care Med. 2019:47(9):1243-50

8. Kim MM, Barnato AE, Angus DC, Fleisher LF, Kahn JM. The effect of multidisciplinary care teams on intensive care unit mortality. Arch Intern Med. 2010;170(4):369-76.

9. Tasaka Y, Tanaka A, Yasunaga D, Asakawa T, Araki H, Tanaka M. Potential drug-related problems detected by routine pharmaceutical interventions: safety and economic contributions made by hospital pharmacists in Japan. J Pharm Health Care Sci. 2018;4(1):1-11.

10. Anderson RD. Mirror to ASHP: 1942-1992. Am J Hosp Pharm. 1992;49(8):1925-35

11. Li X-x, Zheng S-q, Gu J-h, Huang T, Liu F, Ge Q-g, et al. Drug-Related Problems Identified During Pharmacy Intervention and Consultation: Implementation of an Intensive Care Unit Pharmaceutical Care Model. Front Pharmacol. 2020:11:1417.

12. Howle LM, Kirkpatrick CM, Trethewy CE. Clinical pharmacy in a regional Australian intensive care unit. J Pharm Pract Res. 2018;48(1):36-43.

13. Tsang S, Royse CF, Terkawi AS. Guidelines for developing, translating, and validating a questionnaire in perioperative and pain medicine. Saudi Anaesth. 2017;11(Suppl 1):S80-9.

14. Daniel WW, Cross CL. Biostatistics: a foundation for analysis in the health sciences: Wiley; 2018

15. Pharmaceutical Care Network Europe (PCNE). The PCNE classifcation for drug related problems (V 8.02). 2017. https://www.pcne.org/upload/fles/ 230_PCNE_classifcation_V8-02.pdf. Last accessed July 2019

16. Jiang S-P, Chen J, Zhang X-G, Lu X-Y, Zhao Q-W. Implementation of pharmacists' interventions and assessment of medication errors in an intensive care unit of a Chinese tertiary hospital. Ther Clin Risk Manag. 2014;10:861.

17. Martins RR, Silva LT, Lopes FM. Impact of medication therapy management on pharmacotherapy safety in an intensive care unit. Int J Clin Pharm. 2019:41(1):179-88.

18. Sakuma M, Ida H, Nakamura T, Ohta Y, Yamamoto K, Seki S, et al. Adverse drug events and medication errors in Japanese paediatric inpatients: a retrospective cohort study. BMJ Qual Saf. 2014;23(10):830-7.
19. Kim JM, Park SJ, Sohn YM, Lee YM, Yang CS, Gwak HS, et al. Development of clinical pharmacy services for intensive care units in Korea. Springerplus. 2014:3(1):1-7.

20. Kjeldsen LJ, Birkholm T, Fischer H, GraabækT, Kibsdal KP, Ravn-Nielsen $\mathrm{LV}$, et al. Characterization of drug-related problems identified by clinical pharmacy staff at Danish hospitals. Int J Clin Pharm. 2014;36(4):734-41.

21. Ho CK, Mabasa VH, Leung VW, Malyuk DL, Perrott JL. Assessment of clinical pharmacy interventions in the intensive care unit. Can J Hosp Pharm. 2013:66(4):212.

22. Jiang S-P, Zhu Z-Y, Wu X-L, Lu X-Y, Zhang X-G, Wu B-H. Effectiveness of pharmacist dosing adjustment for critically ill patients receiving continuous renal replacement therapy: a comparative study. Ther Clin Risk Manag. 2014;10:405.

23. Jiang S-P, Xu Y-Y, Wu W-F, Zhang X-G, Lu X-Y, Xiao Y-H, et al. Improving antimicrobial dosing in critically ill patients receiving continuous venovenous hemofiltration and the effect of pharmacist dosing adjustment. Eur J Intern Med. 2014;25(10):930-5.

24. Kubas MA, Halboup AM. Implementation of clinical pharmacist recommendations and services at a University Hospital in Yemen. Int J Clin Pharm. 2019:42(1):51-6.

25. Al-azzam SI, Shara M, Alzoubi KH, Almahasneh FA, Iflaifel MH. Implementation of clinical pharmacy services at a university hospital in Jordan. Int J Pharm Pract. 2013;21(5):337-40.

26. Smithburger PL, Buckley MS, Culver MA, Sokol S, Lat I, Handler SM, et al. A multicenter evaluation of off-label medication use and associated adverse drug reactions in adult medical intensive care units. Crit Care Med. 2015:43(8):1612

27. Falagas ME, Kasiakou SK, Saravolatz LD. Colistin: the revival of polymyxins for the management of multidrug-resistant gram-negative bacterial infections. Clin Infect Dis. 2005;40(9):1333-41.

28. Reis AMM, Cassiani SHDB. Adverse drug events in an intensive care unit of a university hospital. Eur J Clin Pharmacol. 2011;67(6):625-32.

29. Abunahlah N, Elawaisi A, Velibeyoglu FM, Sancar M. Drug related problems identified by clinical pharmacist at the Internal Medicine Ward in Turkey. Int J Clin Pharm. 2018;40(2):360-7.

30. Ertuna E, Arun MZ, Ay S, Koçak FÖK, Gökdemir B, Ispirli G. Evaluation of pharmacist interventions and commonly used medications in the geriatric ward of a teaching hospital in Turkey: A retrospective study. Clin Interv Aging. 2019;14:587

31. Spriet I, Meersseman W, De Hoon J, Von Winckelmann S, Wilmer A, Willems L. Mini-series: II. Clinical aspects. Clinically relevant CYP450-mediated drug interactions in the ICU. Intensive Care Med. 2009:35(4):603-12.

32. Magnuson BL, Clifford TM, Hoskins LA, Bernard AC. Enteral nutrition and drug administration, interactions, and complications. Nutr Clin Pract. 2005;20(6):618-24.

33. Allen JM. Vasoactive substances and their effects on nutrition in the critically ill patient. Nutr Clin Pract. 2012;27(3):335-9.

34. Akt P, Lortholary O, Fauvelle F, Tod M, Genereau T, Louchahi M, et al. Pharmacokinetics of teicoplanin during plasma exchange. Clin Microbiol Infect. 1999;5(4):213-8.

35. Fauvelle F, Lortholary O, Tod M, Guillevin L, Louchahi M, Léon A, et al. Pharmacokinetics of ceftriaxone during plasma exchange in polyarteritis nodosa patients. Antimicrob Agents Chemother. 1994:38(7):1519-22.

36. Chiang LH, Huang YL, Tsai TC. Clinical pharmacy interventions in intensive care unit patients. J Clin Pharm Ther. 2021:46(1):128-33.

\section{Publisher's Note}

Springer Nature remains neutral with regard to jurisdictional claims in published maps and institutional affiliations. 